\title{
Increasing costs provoke fall in dental visits
}

Research commissioned by the Oral Health Foundation found more than one-in-three (36\%) Britons admit that they are sacrificing dental visits in order to keep their bank balance in check.

This figure has more than doubled in the last two years. In 2017 , money worries accounted for just $17 \%$ of the reasons for non-attendance.

Chief Executive of the Oral Health Foundation, Dr Nigel Carter $\mathrm{OBE}$, is urging the government to review its decision earlier this year to increase NHS dental charges by $5 \%$.

Dr Carter said: 'The cost of visiting an NHS dentist is increasing far beyond that of inflation and pushing many of the population to breaking point. The decision to yet again raise the cost of check-ups will hit the poorest areas of society even harder and force even more people to avoid dental visits. A significant U-turn needs to take place to make NHS-provided dentistry more affordable. More and more members of the public are calling our Dental Helpline for advice on how to tackle the increasing costs and lack of accessibility to the most basic of dental services. Things have to change, and it should begin with the reviewing of dental charges.'

Further findings from the charity's research show that younger adults are most likely to financially struggle with their oral health.
Just under two-in-three (59\%) 18-24-year-olds freely admit to their financial inability to look after their mouth, teeth and gums.

In recent years, younger generations have been hit hard with rising university costs, rent and housing fees and growing insurance prices. The charity fears that increasing NHS dental charges could discourage young adults from maintaining good oral health.

'The rising costs of NHS dentistry are unsustainable, said Dr Carter. 'Young people, families on lower incomes, and the elderly, are all at risk of being alienated. The government must be working to encourage people towards NHS dentistry, not driving them away.'

The study also found that more than one-in-ten Britons (11\%) admit to having no designated dentist, while just under one-in-five (16\%) say they only go to the dentist when they believe they have a problem.

Cost is not the only reason behind not attending a dentist. Anxiety (22\%), the fear of getting bad news (18\%) and work commitments (8\%), are all reasons why people stay away.

Dr Carter also expressed concern at the government's unwillingness to commit to a sustained level of NHS dentistry funding and warned of further problems if this isn't addressed swiftly.

Net government expenditure in England on dental services has dropped by $£ 550$ million in real terms since 2010 . Over the same period, the cost of NHS dentistry has increased by more than $30 \%$.

\section{Here has been an advertisement.}

\section{Trainers' Trainer of the Year}

Consultant maxillofacial surgeon Daljit Dhariwal received the 2019 Trainers' Trainer of the Year award at the recent British Association of Oral and Maxillofacial Surgeons (BAOMS) annual scientific conference.

'I am humbled and delighted because it comes from the trainees,' said Dr Dhariwal on winning the award.

Dr Dhariwal works part time as a consultant

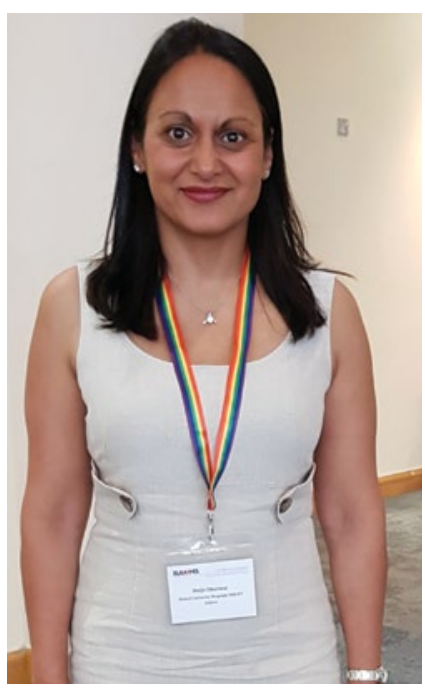

maxillofacial surgeon at the John Radcliffe Hospital in Oxford.

The Trainers' Trainer competition starts each January when all UK OMFS trainees are invited by Alistair Smyth, Recruitment and Retention Lead for BAOMS Council, to nominate the best trainer on their rotation.

'I see my role as doing what I can to help [the trainees] realise their potential to come out of training to be able to progress their practice and in future come back and teach me!' said Dr Dhariwal. 'It's the ultimate goal.' 